\title{
Behind the Prescriptions
}

A snapshot of opioid use across all Ontarians

\section{ODPRN}

A Report by the Ontario Drug Policy Research Network August 22, 2017 


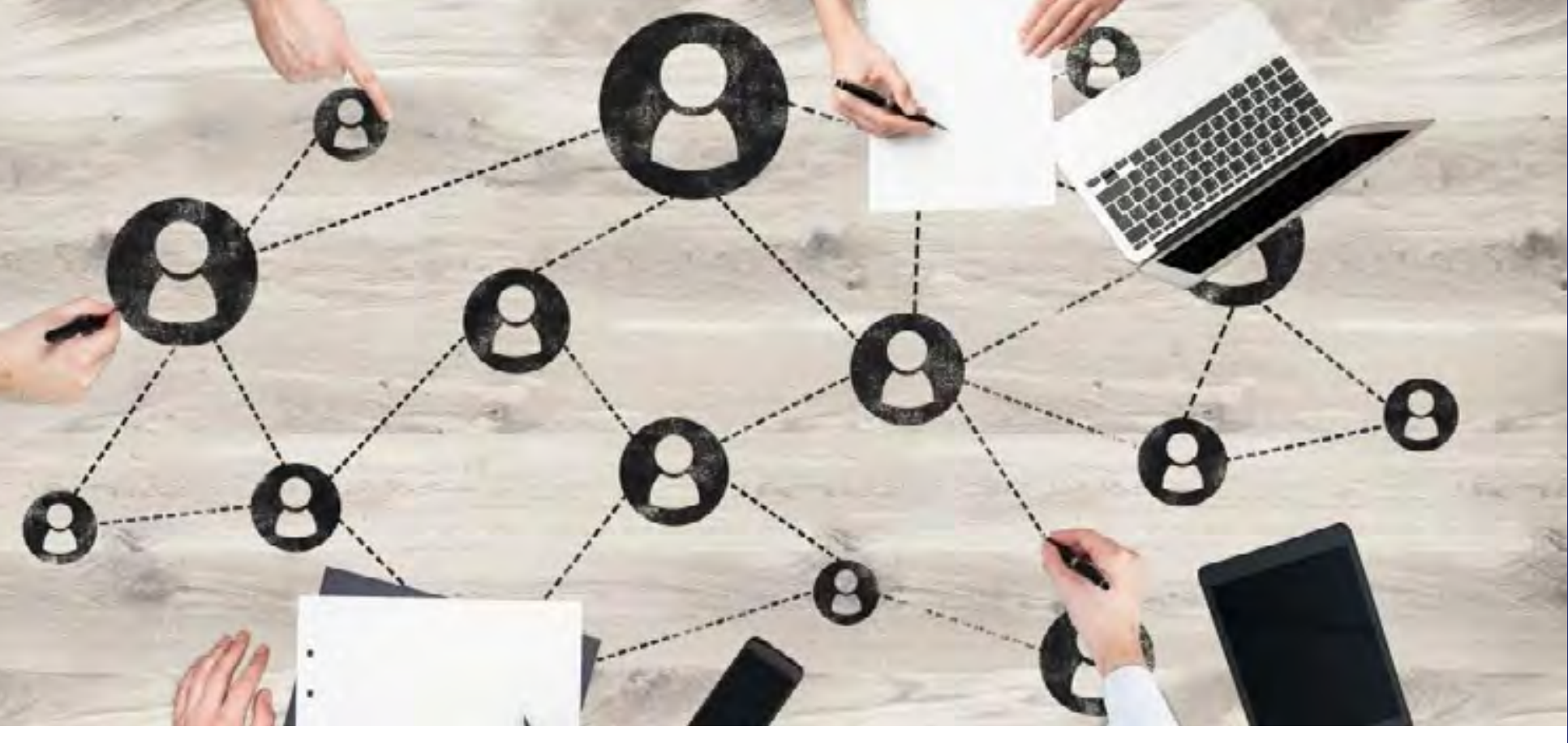

\section{About the ODPRN}

The Ontario Drug Policy Research Network (ODPRN) is a province-wide network of researchers who provide timely, high quality, drug policy relevant research to decision makers. The ODPRN's core principles are quality, relevance, and timeliness. We conduct research to determine real-world drug utilization, safety, effectiveness, and costs of drugs in Ontario, and have developed partnerships that allow us to engage in cross-provincial comparisons of drug safety and utilization.

We are funded to conduct pharmacoepidemiologic and drug policy research as part of an initiative to provide evidence to inform policy at the Ontario Ministry of Health and Long-Term Care (MOHLTC). As such, the ODPRN works closely with the Ontario Public Drug Programs (OPDP), MOHLTC and other stakeholders to select key priority areas and topics for analysis.

\section{How to cite this report:}

Gomes T, Pasricha S, Martins D, Greaves S, et al. Behind the Prescriptions: A snapshot of opioid use across all Ontarians. Toronto: Ontario Drug Policy Research Network; August 2017.

\section{For more information about the ODPRN and the work we do:}

www.odprn.ca

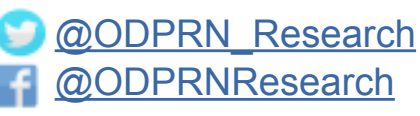

\section{Contact}

Ontario Drug Policy Research Network

St. Michael's Hospital

30 Bond St., Toronto, ON, M5B 1W8

info@odprn.ca 


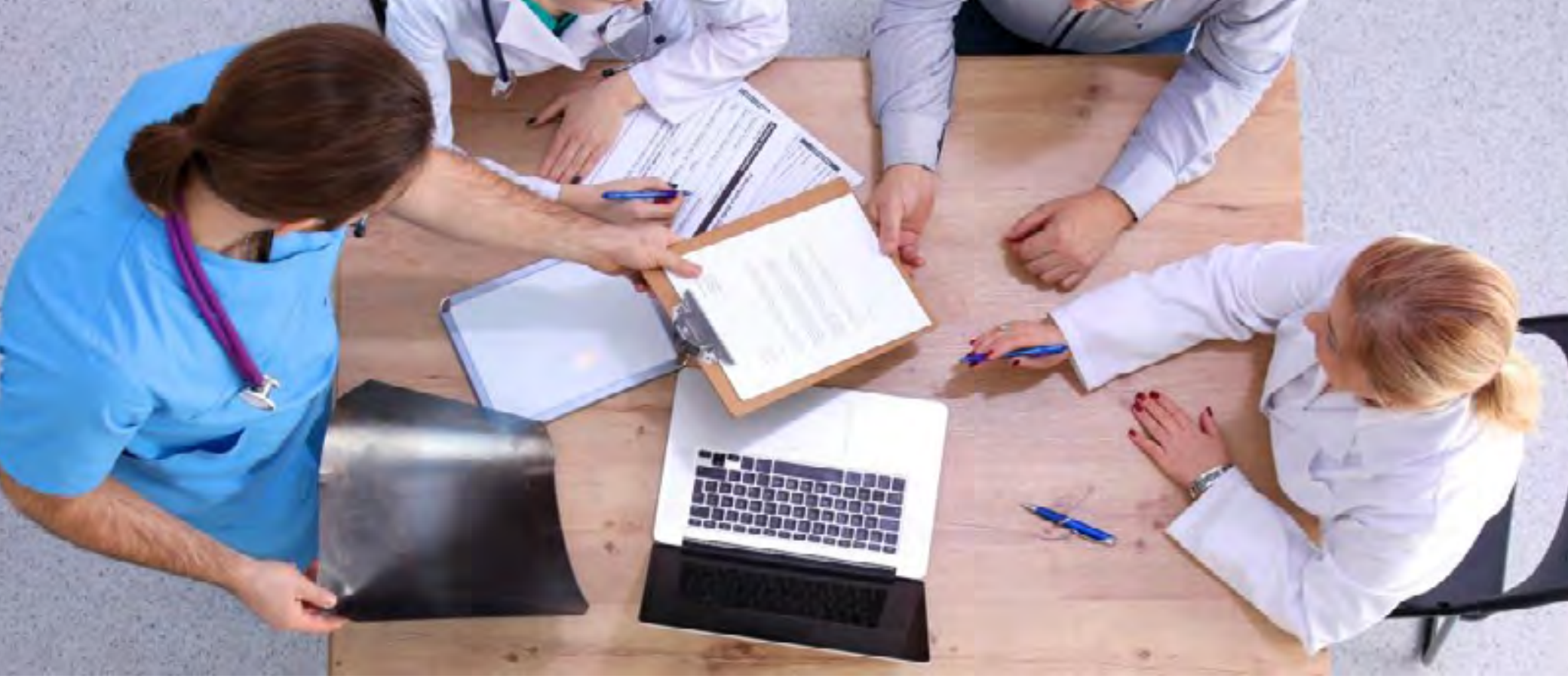

\section{Acknowledgements}

This study was supported by grants from the Ontario Ministry of Health and Long-Term Care (MOHLTC) and the Ontario Strategy for Patient-Orientated Research (SPOR) Support Unit which is supported by the Canadian Institutes of Health Research and the Province of Ontario. The work was also supported by the Institute for Clinical Evaluative Sciences (ICES), which is funded by an annual grant from the Ontario Ministry of Health and Long-Term Care (MOHLTC). The opinions, results and conclusions reported in this paper are those of the authors and are independent from the funding sources. No endorsement by ICES, the Ontario SPOR Support Unit or the Ontario MOHLTC is intended or should be inferred.

We thank the Office of the Chief Coroner for Ontario for project facilitation and their assistance with data retrieval. Parts of this material are based on data and/or information compiled and provided by $\mathrm{ClHI}$. However, the analyses, conclusions, opinions and statements expressed in the material are those of the author(s), and not necessarily those of $\mathrm{ClHI}$. A special thanks to Dr. Dirk Huyer for his input and feedback on previous versions of this report.

\section{Study Team}

Tara Gomes

Sachin Pasricha

Diana Martins

Simon Greaves

Mina Tadrous
Dana Bandola

Samantha Singh

Michael Paterson

Muhammad Mamdani

David Juurlink

\section{Citizens' Panel Representatives}

Terry Ebejer

Anne MacDonald

Kristen Morin 


\section{Contents}

$\begin{array}{lr}\text { Background } & 5\end{array}$

$\begin{array}{lr}\text { Methods } & 5\end{array}$

$\begin{array}{lc}\text { Setting } & 5\end{array}$

$\begin{array}{lc}\text { Types of Opioids } & 5\end{array}$

$\begin{array}{lc}\text { Opioid Use } & 6\end{array}$

$\begin{array}{lc}\text { Dose for Opioids } & 6\end{array}$

$\begin{array}{lc}\text { Characteristics of Opioid Use } & 6\end{array}$

$\begin{array}{ll}\text { Geographical Variation } & 7\end{array}$

$\begin{array}{lr}\text { Key Findings } & 7\end{array}$

$\begin{array}{ll}\text { Characteristics of Opioid Use in Ontario } & 7\end{array}$

$\begin{array}{ll}\text { Geographic Variations in Opioid Prescribing } & 10\end{array}$

$\begin{array}{ll}\text { Opioids to Treat Pain } & 14\end{array}$

$\begin{array}{lr}\text { Opioids to Treat Cough } & 18\end{array}$

$\begin{array}{ll}\text { Opioids to Treat Addiction } & 19\end{array}$

$\begin{array}{lr}\text { Discussion } & 20\end{array}$

$\begin{array}{ll}\text { Conclusion } & 21\end{array}$

$\begin{array}{lr}\text { References } & 21\end{array}$

$\begin{array}{lr}\text { Appendix } & 22\end{array}$ 


\section{Background}

Opioids are a group of drugs commonly prescribed to treat pain. Some drugs in the class can also be used as cough suppressants or as treatments for opioid addiction. The safety of prescription opioid use and the rate at which these medications are being prescribed has been of considerable concern across Ontario over the past twenty years. ${ }^{1}$ In particular, studies have shown that opioids are being increasingly prescribed, and that higher doses and co-prescription with other drugs (such as benzodiazepines) can increase the risk of overdoses. ${ }^{2}$ The provincial population-based databases housed at Ontario's Institute for Clinical Evaluative Sciences (ICES) serve as an important resource for studying the utilization and outcomes associated with opioids for the populations covered under the public drug plan. However, due to data limitations, much of the research using these databases has been limited to sub-groups of Ontarians, such as seniors and social assistance recipients. ${ }^{3,4}$ This has left many gaps in our understanding of how opioids are prescribed to the general population, and how these patterns vary by age, sex and socioeconomic status.

In 2012, the Ontario government launched the Narcotics Monitoring System (NMS) - a prescription monitoring program that captures all prescription opioids dispensed in the province. ${ }^{5}$ The intent of the NMS was to provide more data to front-line healthcare professionals to help support safe and appropriate narcotic prescribing, and to generate data that could be used to monitor and evaluate the patterns in prescribing across the province. Health Quality Ontario (HQO), the first to release a public report that analyzed these data in early 2017 , showed that approximately 1 in 7 people in Ontario received a prescription opioid in 2015/16, and that opioid prescribing rates have continued to climb over the past several years. ${ }^{6}$ This report builds on that work, using the NMS to describe more detailed patterns of opioid use, and also links the dispensing data to health care and demographic databases which allows us to better characterize who is being treated with opioids in Ontario. Finally, throughout the report, we describe people who are treated with opioids for each of three broad indications: pain (both cancer-related and non-cancer related), cough, and addiction. Overall, the core objective of this report is to describe characteristics and patterns of opioid use in the entire population of Ontario, including demographics, use of health services, and geographic variations.

\section{Methods}

\section{Setting}

We conducted a cross-sectional study among individuals living in Ontario, who were dispensed an opioid prescription between July 1, 2012 and March 31, 2017. We used data from the NMS, which captures information on dispensed prescriptions for opioids regardless of the type of payment (private insurance, public insurance, or out-of-pocket). We limited the analysis to individuals who presented a valid Ontario health insurance card as their source of identification at the time of prescription dispensing, which accounted for $97 \%$ of prescriptions captured in the NMS. We included all opioids prescribed by registered physicians, surgeons, nurse practitioners, or dentists in Ontario The yearly summaries presented in this report are based on the most recent year for which data are available. This is calendar year 2016 for prescription information, and fiscal year 2015/16 (April 1, 2015 to March 31, 2016) for analyses that involved hospital data (i.e. inpatient hospitalizations or emergency department visits). All datasets used in this study were linked using unique, encoded identifiers and analyzed at the Institute for Clinical Evaluative Sciences (ICES; www.ices.on.ca) using SAS Enterprise Guide Version 6.1.

\section{Types of Opioids}

Opioids included in this report were stratified into three mutually-exclusive groups by indication, including those used to treat pain, those to treat opioid addiction, and those used as cough suppressants. Opioids indicated for pain were further stratified by the type of formulation (long- 
acting and immediate-release) and type of drug (codeine, fentanyl, hydromorphone, oxycodone, etc.). Opioids used to treat addiction were reported overall and by type of drug (methadone and buprenorphine/naloxone). Opioids used as cough suppressants in Ontario include codeine, hydrocodone and normethadone.

\section{Opioid Use}

We report the number of individuals with a valid health card who were dispensed an opioid prescription in Ontario. We calculated the rate of opioid use as the number of individuals who were dispensed an opioid divided by the population in Ontario, using estimates from Statistics Canada as the denominator, and reported this per 100 individuals. Rates were reported monthly between July 1, 2012 and March 31, 2017, and overall in calendar year 2016. These measures were reported by indication (i.e. pain, cough or addiction) and formulation.

Important Note: The indication groups are not mutually exclusive, meaning if an individual was dispensed an opioid for pain and a separate prescription for cough, they were placed in both groups. Similarly, if a person received both a long-acting and an immediate-release opioid for the indication of pain, they were reported in both formulation groups.

\section{Dose for Opioids}

Opioid dose dispensed was reported as milligrams of morphine or equivalent (mg MEQ). This is calculated by converting the dose on each opioid prescription dispensed into its equivalent dose in morphine. This allows for comparisons of doses between different types of opioid drugs dispensed. The total volume of opioids dispensed was calculated by adding the mg MEQ on all prescriptions dispensed in the time period of interest. Daily dose was calculated using the MEQ on opioid prescriptions divided by the days' supply. Of note, we did not calculate opioid dose for opioids used for pain when no accurate dose conversion was available, which includes rarely used opioids and opioids administered through non-oral or non-transdermal routes. Additionally, opioid dose for opioids used for addiction therapy were not calculated due to data quality limitations.

\section{Characteristics of Opioid Use}

Demographic characteristics were captured for all individuals dispensed an opioid between January 1, 2016 and December 31, 2016, including age, sex, location of residence (urban vs. rural), and income quintile using information obtained from the Ontario Health Insurance Plan (OHIP) Registered Persons Database (RPDB). We also calculated the proportion of individuals who were dispensed a benzodiazepine or stimulant drug in the 90 days prior to their first opioid prescription in the year because of the increased risks that can occur when opioids are combined with these drugs. The rates of individuals who were dispensed an opioid were presented overall, by age group (0-18, 19-24, 25-44, $45-64,65+)$ and by sex.

Among people dispensed an opioid to treat pain, we reported numbers by type of formulation and type of drug, and stratified the population according to whether they were a new or ongoing user. New users were defined as those without an opioid prescription in the year prior to their first filled prescription in 2016. A number of patient- and prescription-level characteristics were captured and compared between new and ongoing users, including the median number of prescriptions per user, the prevalence of concurrent use of opioids and benzodiazepines (defined as more than 7 days of overlapping use), the median number of units (e.g. pills, tablets, patches) dispensed, the median duration of prescriptions, and the percentage with daily dose $\leq 50 \mathrm{mg}$ MEQ, 51-90mg MEQ and $>90 \mathrm{mg}$ MEQ.

Between April 1, 2015 and March 31, 2016, we also captured health services utilization among individuals dispensed an opioid, stratified by the indication for opioid use. Specifically, we reported the number of physician visits in the year prior to the first opioid prescription dispensed in the year using the OHIP claims database, and the proportion 
of people with a hospitalization or emergency department (ED) visit in the preceding year using data from the Canadian Institute for Health Information Discharge Abstract Database (ClHIDAD) and CIHI National Ambulatory Care Reporting System (CIHI-NACRS) Database, respectively. ED visits for opioid toxicity in the past year were also captured using International Classification of Diseases, Version 10 (ICD-10) codes T40.0, T40.1, T40.2, T40.3, T40.4 and T40.6. In this analysis, we included the primary diagnosis ("main problem") and any secondary diagnoses, but excluded those that were not definitive ("suspected") and any "scheduled" visits.

\section{Geographical Variation}

Regional variation in opioid dispensing was illustrated by mapping opioid dispensing rates according to Public Health Unit (PHU) and Local Health Integration Network (LHIN; Ontario's regional health planning authorities) from January 1, 2016 to December 31, 2016. Location of residence was based on the individual's postal code at the time of the first opioid prescription in the study year. The denominator was obtained using population estimates in 2016 from Statistics Canada.

Separate maps were created by indication (pain, cough or addiction). Furthermore, separate maps were created to illustrate regional variation in the rate of use of methadone and buprenorphine/ naloxone separately. We also depicted regional variation in annualized rates of opioid-related deaths between July 1, 2013 and June 30, 2016 using data abstracted from the Office of the Chief Coroner of Ontario. Three-year annualized rates were presented to avoid suppression of small annual counts in some regions. Here, location of residence was based on the individual's postal code on the date of death, and estimated population denominators were obtained from Statistics Canada.

\section{Key Findings}

\section{Characteristics of Opioid Use in Ontario}

- In 2016, 1 in 7 Ontarians were dispensed an opioid, with the majority (85\%) receiving an opioid for the treatment of pain.

- More women than men received an opioid to treat pain or cough, while the reverse was true for opioids to treat addiction with more men than women being dispensed prescriptions.

- Opioid use to treat pain or cough was evenly distributed across income brackets, while those receiving opioids for addiction therapy were concentrated in lower incomes.

- Recent use of benzodiazepines and stimulants was common among people dispensed opioids to treat both pain and addiction.
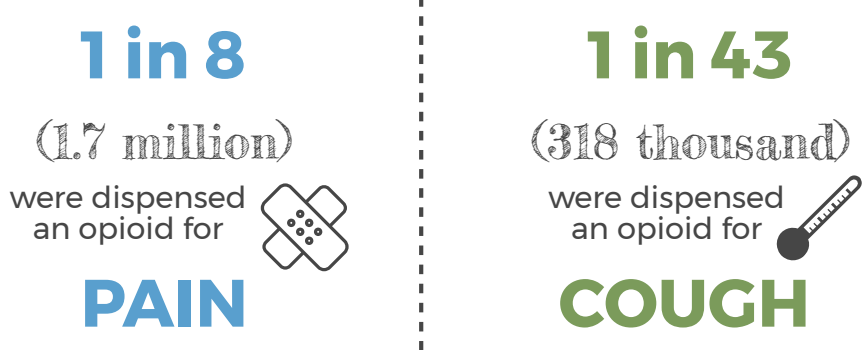

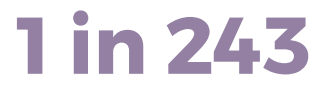

(58 thoursand)

were dispensed an opioid for
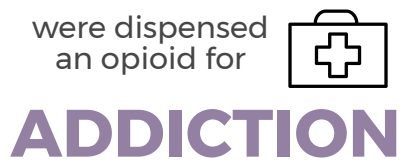
In 2016,1 in 7 Ontarians $(1,954,473$ of $13,982,984$ population; $14.0 \%$ ) were dispensed an opioid. When considering the indication for opioid use, $11.9 \%$ of Ontarians $(1,663,181$ individuals; 1 in 8 Ontarians) were dispensed an opioid indicated for pain, 2.3\% (317,890 individuals; 1 in 43 Ontarians) were dispensed an opioid indicated for cough suppression, and $0.4 \%$ (57,509 individuals; 1 in 243 Ontarians) were dispensed an opioid for addiction treatment.

\section{Age}

The number and percent of people dispensed an opioid in Ontario varied by age and indication (Table 1). Overall, among individuals who received an opioid for pain, the median age was 55 years. The proportion of people who received an opioid increased with age, with the highest percent among those aged 65 and older (22.0\%). However, the age group with the largest absolute number of people dispensed an opioid for pain was those aged 45 to 64 years $(\mathrm{N}=626,968 ; 16.0 \%)$. This high prevalence of opioid use in older age groups could be influenced by the use of these drugs to treat cancerrelated pain, post-surgical pain (i.e. after hip or knee surgeries) and palliative care. Among individuals dispensed an opioid for cough, the median age was slightly younger at 49 years, and the rate of use was highest among individuals aged 45 to 64 . Finally, individuals treated with opioids for addiction were generally younger (median 36 years), and the highest rate of use was among those aged 25 to 44 years $(1.0 \%)$.

\section{Sex}

Opioid dispensing also varied by sex, with fewer men than women dispensed an opioid to treat pain ( $11.0 \%$ of men vs. $12.8 \%$ of women) and cough ( $1.9 \%$ of men vs. $2.6 \%$ of women). This pattern aligns with those identified in the United States where women are also more likely to be prescribed opioids than men. ${ }^{7}$ Previous research suggests that these patterns could be due to higher rates of chronic pain among women, or prescribers being more likely to treat women with opioids at higher doses for longer periods of time. ${ }^{8}$ However, the proportion of people being treated for opioid addiction was higher among men $(0.5 \%)$ compared to women $(0.3 \%)$. This could be influenced by a number of factors, including the differing patterns of injection drug use between men and women., 9,10

\section{Residence and Income}

Overall, similar to the general Ontario population (89\% residing in urban locations), the vast majority of individuals dispensed an opioid in 2016 resided in urban settings (Table 2). However, this differed slightly by indication, with almost all those who received an opioid to treat cough residing in urban settings (95\%) compared to slightly less among those dispensed an opioid to treat pain $(87 \%)$ and addiction (86\%). Interestingly, although individuals

\begin{tabular}{|c|c|c|c|c|}
\hline \multicolumn{5}{|c|}{$\begin{array}{c}\text { Table 1. Number and percent of all Ontarians dispensed an opioid, } \\
\text { by demographic group, } 2016\end{array}$} \\
\hline & & Pain $(\mathbf{N}, \%)$ & Cough (N, \%) & Addiction (N, \%) \\
\hline \multicolumn{2}{|c|}{ All people dispensed opioids } & $1,663,181(11.9)$ & $317,890(2.3)$ & $57,509(0.4)$ \\
\hline \multirow{5}{*}{ Age Group } & $0-18$ & $71,466(2.5)$ & $26,821(0.9)$ & $205(0.01)$ \\
\hline & $19-24$ & $86,737(7.4)$ & $15,476(1.3)$ & $4,978(0.4)$ \\
\hline & $25-44$ & $372,458(10.0)$ & $88,977(2.4)$ & $35,769(1.0)$ \\
\hline & $45-64$ & $626,968(16.0)$ & $123,205(3.2)$ & $15,662(0.4)$ \\
\hline & $65+$ & $503,341(22.0)$ & $63,000(2.8)$ & $770(0.03)$ \\
\hline \multirow{2}{*}{ Sex } & Men & $753,205(11.0)$ & $133,304(1.9)$ & $36,120(0.5)$ \\
\hline & Women & $907,765(12.8)$ & $184,175(2.6)$ & $21,264(0.3)$ \\
\hline
\end{tabular}

Note: These are the percentages of all Ontarians within each demographic group that were dispensed an opioid for each indication. 


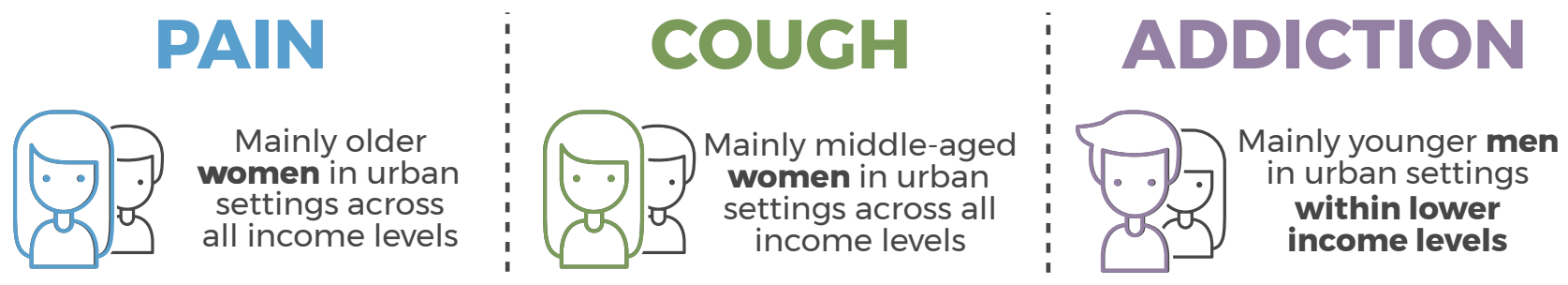

Table 2. Characteristics of people dispensed an opioid, 2016

\begin{tabular}{|l|l|c|c|c|}
\multicolumn{2}{l|}{} & \multicolumn{1}{|c|}{ Pain } & Cough & Addiction \\
\hline \multicolumn{2}{|l|}{ Median Age (Q1, Q3) } & S5(39-68) & $49(35-61)$ & $36(29-46)$ \\
\hline \multirow{2}{*}{ Sex (N, \%) } & Male & $753,205(45 \%)$ & $133,304(42 \%)$ & $36,120(63 \%)$ \\
\cline { 2 - 5 } & Female & $907,765(55 \%)$ & $184,175(58 \%)$ & $21,264(37 \%)$ \\
\hline \multirow{2}{*}{ Residence (N, \%) } & Urban & $1,442,589(87 \%)$ & $300,890(95 \%)$ & $49,254(86 \%)$ \\
\cline { 2 - 5 } & Rural & $214,628(13 \%)$ & $15,586(5 \%)$ & $7,995(14 \%)$ \\
\hline \multirow{3}{*}{ Income Quintile (N, \%) } & Lowest & $343,856(21 \%)$ & $58,566(18 \%)$ & $20,542(36 \%)$ \\
\cline { 2 - 5 } & 2nd Lowest & $334,608(20 \%)$ & $69,236(22 \%)$ & $12,927(23 \%)$ \\
\cline { 2 - 5 } & Middle & $329,657(20 \%)$ & $70,533(22 \%)$ & $9,493(17 \%)$ \\
\cline { 2 - 5 } & 2nd Highest & $336,814(20 \%)$ & $66,095(21 \%)$ & $7,853(14 \%)$ \\
\cline { 2 - 5 } & Highest & $306,555(18 \%)$ & $51,444(16 \%)$ & $5,822(10 \%)$ \\
\hline
\end{tabular}

Note: These are the percentages of people dispensed an opioid for each indication within each demographic group.

receiving an opioid to treat pain and cough were relatively evenly distributed among income quintiles, the use of opioids to treat addiction is concentrated in the lower income groups, with $58 \%$ of individuals dispensed an opioid for addiction treatment being in the lowest two income quintiles. These findings are important, as previous research in Ontario has been limited to populations who are eligible for public drug benefits, and who are therefore more likely to be of lower socio-economic status. ${ }^{3}$ This report among all residents of Ontario suggests that while opioid dispensing for pain and cough occurs similarly across income groups, individuals with lower income were more likely to be receiving treatment for opioid use disorder.

\section{Recent Medication Use}

The degree of recent use of benzodiazepines was noteworthy, reaching $14 \%$ among individuals dispensed opioids to treat pain and $17 \%$ among those dispensed opioids to treat addiction. Although recent use of stimulants was relatively rare among those treated for pain or cough (1\%), $5 \%$ of individuals receiving an opioid for addiction were dispensed a stimulant in the past 3 months. This pattern of potential co-prescription of controlled substances is concerning given the increased risks associated with the use of these drugs together. ${ }^{2}$

Percentage of people dispensed an opioid for

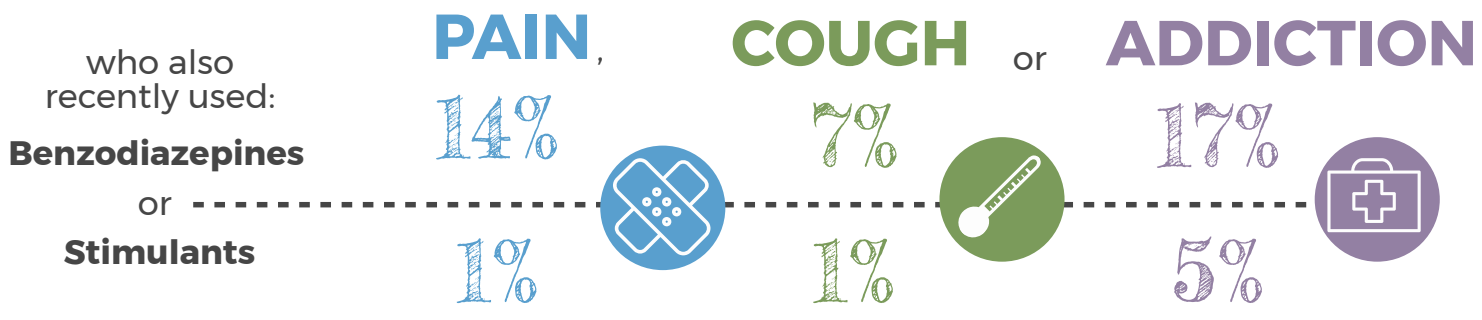




\section{Use of the Healthcare System}

Use of the health care system differed among individuals dispensed opioids for pain, cough, and addiction (Table 3). People being treated for opioid addiction visited physicians the most, with a median of 42 office visits in a year compared to less than 10 visits per year among those being treated for pain and cough. The higher number of physician office visits among individuals receiving an opioid for addiction treatment is reflective of the nature of opioid maintenance therapy, which generally involves regular physician visits and urine drug screening. ${ }^{11,12}$

ED visits were much more prevalent among people treated with opioids for pain (43\%) and addiction $(47 \%)$ compared to the Ontario average (23\%).
In contrast, the prevalence of ED visits among people treated for cough (25\%) was similar to the provincial average. Further, a higher percentage of people dispensed an opioid to treat pain $(12 \%)$ were hospitalized compared to the general population ( $8 \%)$. This may be reflective of the older age distribution in this group as well as the higher likelihood of receiving an opioid following a surgery or injury that may have been treated in these settings. The high number of hospitalizations among people dispensed an opioid to treat addiction $(10 \%)$ may suggest a high degree of comorbidity in this group, which requires further exploration. Importantly, this pattern does not appear to be driven by opioid overdose incidents, which occurred in only 135 per 10,000 people in this group.

Table 3. Healthcare system usage by people dispensed an opioid prescription, April 12015 - March 312016

\begin{tabular}{|l|c|c|c|}
\hline & Pain & Cough & Addiction \\
\hline Median Physician Visits (Q1, Q3) & $7(3,13)$ & $6(3,11)$ & $42(15,59)$ \\
\hline Emergency Department Visits (N, \%) & $721,795(43 \%)$ & $82,463(25 \%)$ & $25,850(47 \%)$ \\
\hline Hospitalizations (N, \%) & $205,845(12 \%)$ & $17,587(5 \%)$ & $5,302(10 \%)$ \\
\hline Opioid Toxicity Event (N, rate per 10,000) & $1,292(8)$ & $55(2)$ & $744(135)$ \\
\hline
\end{tabular}

\section{Geographic Variations in Opioid Prescribing}

- Higher rates of people dispensed an opioid to treat pain or addictions were concentrated in northwestern and rural regions in Ontario, while higher rates of those receiving an opioid for cough were clustered in southern and urban areas.

- Some regions with high opioid use for addiction treatment had only moderate prescribing for pain, suggesting that illicitly obtained opioids may be large contributors to opioid addiction in these areas.

- In most regions in Ontario, methadone was dispensed at a higher rate than buprenorphine/naloxone for addiction treatment.

\section{To explore using our interactive maps, please visit our website.}

Opioid use varied considerably across the province. Rural areas tended to have more individuals dispensed an opioid to treat pain compared to urban areas (Figure 1). North Bay Parry Sound (17\% of residents) and Haliburton, Kawartha, Pine Ridge (17\% of residents) Health Units had the highest percent of residents receiving opioids for pain. In comparison, the lowest percent of residents who received prescription opioids to treat pain occurred in York Region ( $9 \%$ of residents), Toronto ( $10 \%$ of residents) and Peel (10\% of residents) Public Health Units. 
Figure 1. Geographic variation of people dispensed an opioid to treat pain (percent of residents by public health unit).

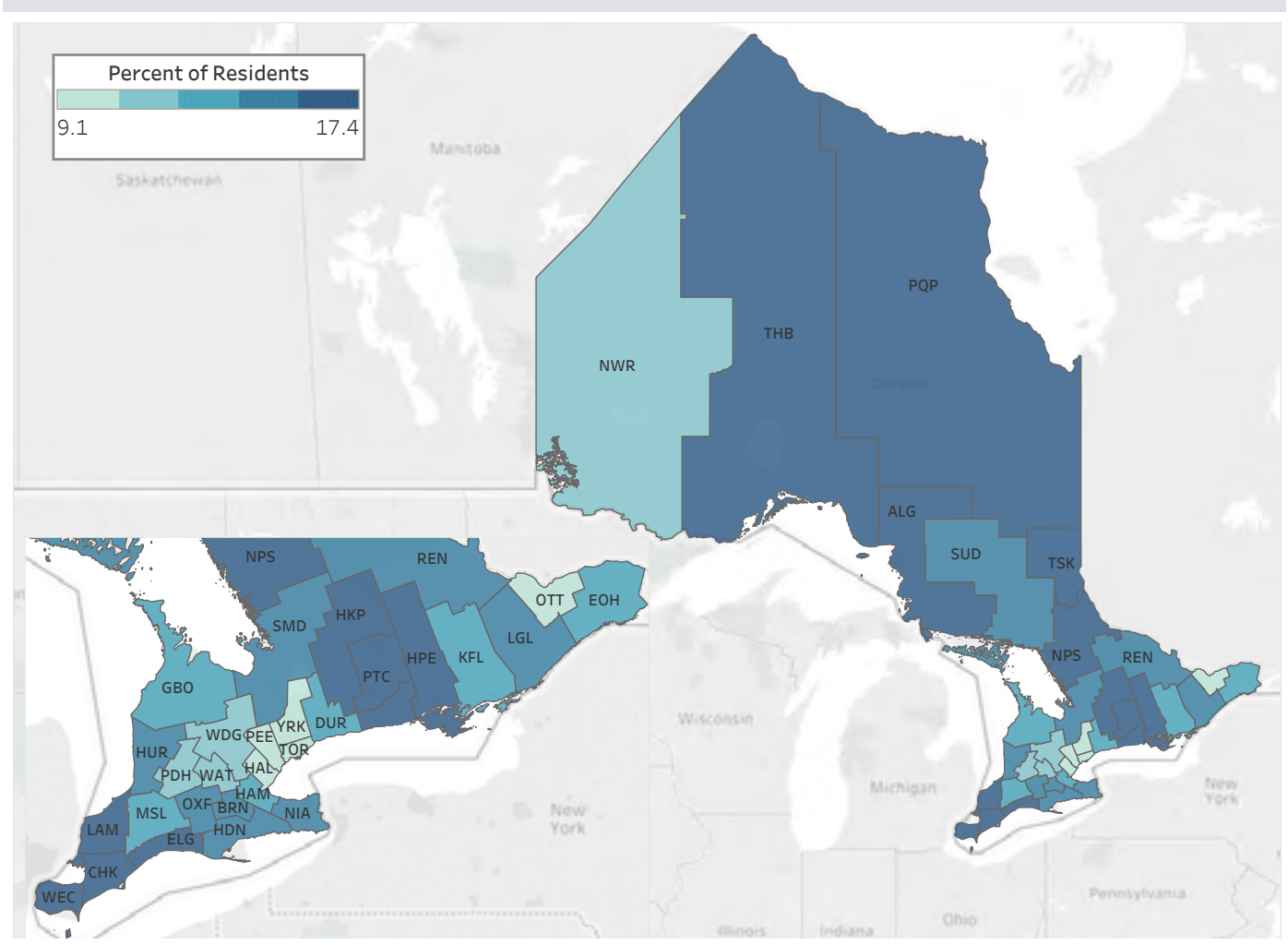

In contrast, high concentrations of individuals dispensed an opioid to treat cough occurred in urban areas in Ontario (Figure 2). In particular, the percentage of residents dispensed an opioid to treat cough was highest in Peel (5\% of residents), York Region (4\% of residents), Windsor-Essex County ( $4 \%$ of residents) and Toronto ( $3 \%$ of residents) Public Health Units.

The percentage of residents dispensed an opioid for addiction treatment was generally higher in northern, western, and rural areas of Ontario (Figure 3), with many similarities among regions with high prescribing of opioids for pain and addiction. Specifically, the highest percentages of residents dispensed opioids to treat addiction were in Thunder Bay District (2\% of residents), Northwestern ( $1 \%$ of residents), Lambton ( $1 \%$ of residents), North Bay Parry Sound District (1\% of residents), and Sudbury and District (1\% of residents) Health Units.

The annualized rate of opioid-related deaths was calculated from 2013-2016, and demonstrated considerable variation across the province, similar to what has been shown in past analyses (Figure 4). ${ }^{3}$ The rates were highest in Thunder Bay District (14.0 per 100,000 residents), Timiskaming (10.9 per 100,000 residents), and Sudbury and District (10.5 per 100,000 residents) Health Units. In contrast, the lowest rates were observed in Eastern Ontario (2.6 per 100,000 residents) and York Region (2.4 per 100,000 residents) Public Health Units.

In general, the areas with fewer individuals dispensed an opioid to treat addiction aligned well with those regions with fewer people dispensed an opioid to treat pain (e.g. York Region, Peel Region). However, there are some important patterns where high opioid prescribing for pain does not align with high prescribing for addiction treatment. For example, although Haliburton, Kawartha, Pine Ridge District, Windsor-Essex County and Porcupine Health Units had among the highest percent of residents dispensed opioids for pain, the percent of residents being treated for addiction were only moderate. Moreover, these three areas 
Figure 2. Geographic variation of people dispensed an opioid to treat cough (percent of residents by public health unit).

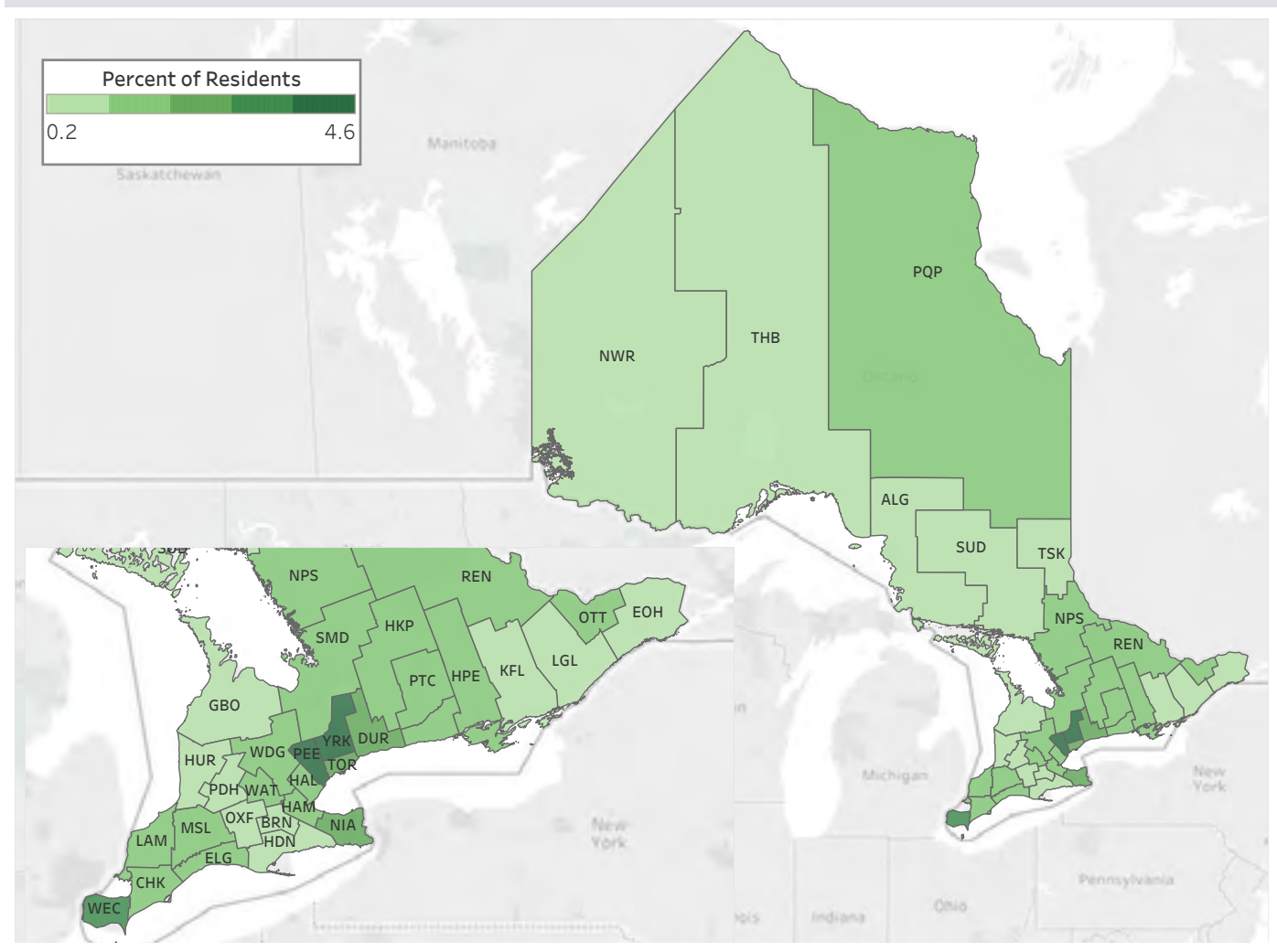

have above average rates of opioid-related death (annualized rates of 5.4, 6.1, and 6.3 per 100,000 residents, respectively; provincial average 5.1 per $100,000)$. The high rates of prescribing for pain and opioid-related death rates in combination with low prescribing for addiction treatment could suggest poor access to addiction treatment services in these regions. In contrast, Thunder Bay District Health Unit had only the 11th highest percentage of residents treated with opioids for pain, but the highest percentage of residents dispensed opioids to treat addiction, as well as the highest rate of opioid-related deaths. Furthermore, the City of Hamilton, Renfrew County and District, and Simcoe Muskoka District Health Units had low opioid prescribing for both pain and addiction, but opioidrelated death rates were relatively high. This could be reflective of greater use of diverted and/or illicit opioid use in these areas, although more work needs to be done to understand the specific drivers of these patterns.
Although methadone has historically been the firstline treatment for opioid use disorder in Ontario, access to buprenorphine/naloxone is increasing. We observed interesting geographic variation in use of methadone versus buprenorphine/naloxone across Ontario. Although some regions (Thunder Bay District Health Unit, Lambton Public Health, Sudbury and District Health Unit) had high use of both of these treatment options, other regions demonstrated large differences in the use of treatments available. For example, Peterborough Public Health and Brant County Health Unit had among the highest rates of methadone use in the province, with lower rates of buprenorphine/naloxone. There were only three regions with a higher rate of buprenorphine/ naloxone use compared to methadone use: Northwestern Health Unit, Renfrew County and District Health Unit, and Ottawa Public Health. More details on regional variation in rates of methadone and buprenorphine/naloxone can be found on our website here. 
Figure 3. Geographic variation of people dispensed an opioid to treat addiction (percent of residents by public health unit).

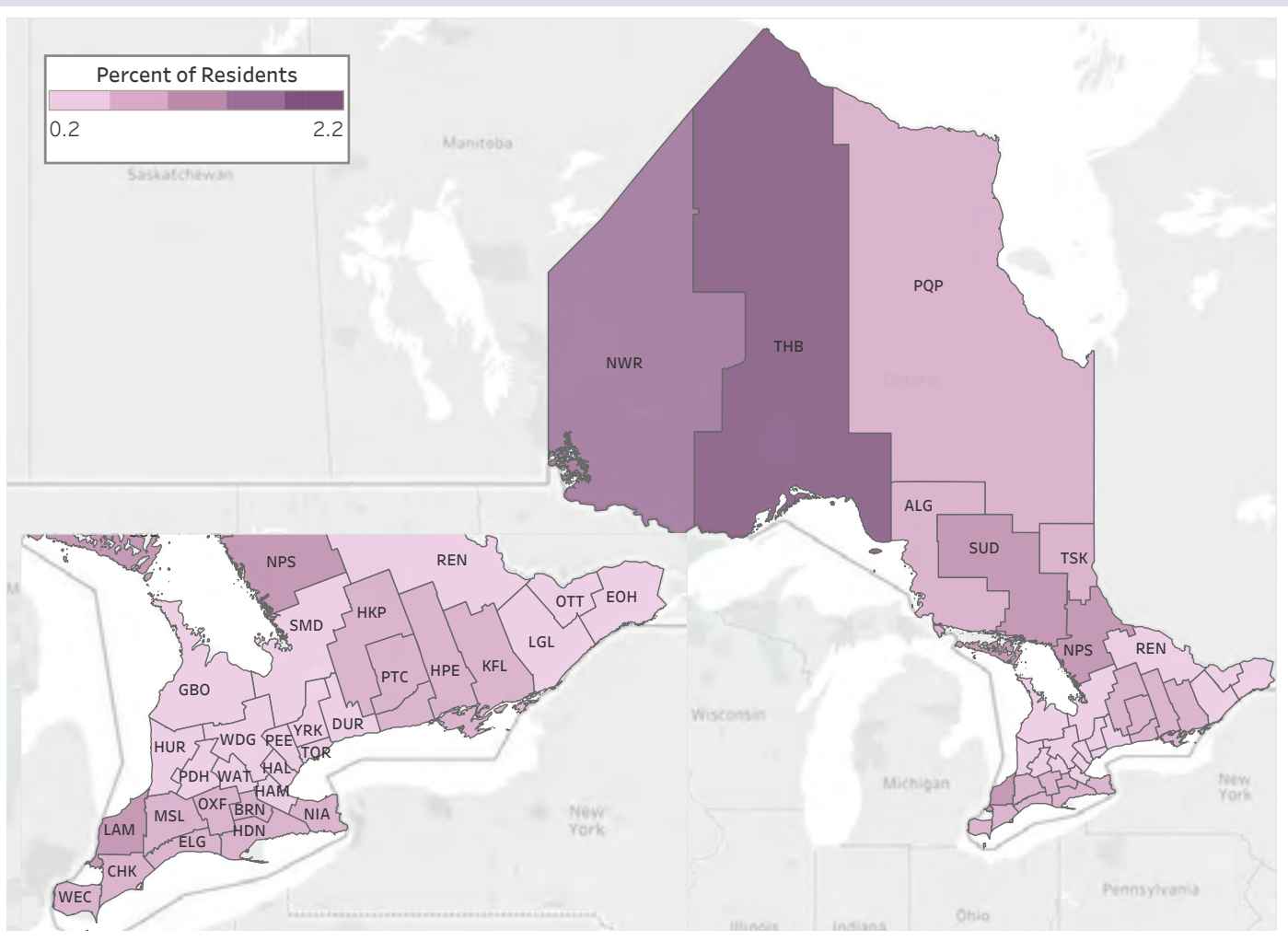

Figure 4. Geographic variation of opioid-related deaths (rate per 100,000 residents by public health unit).

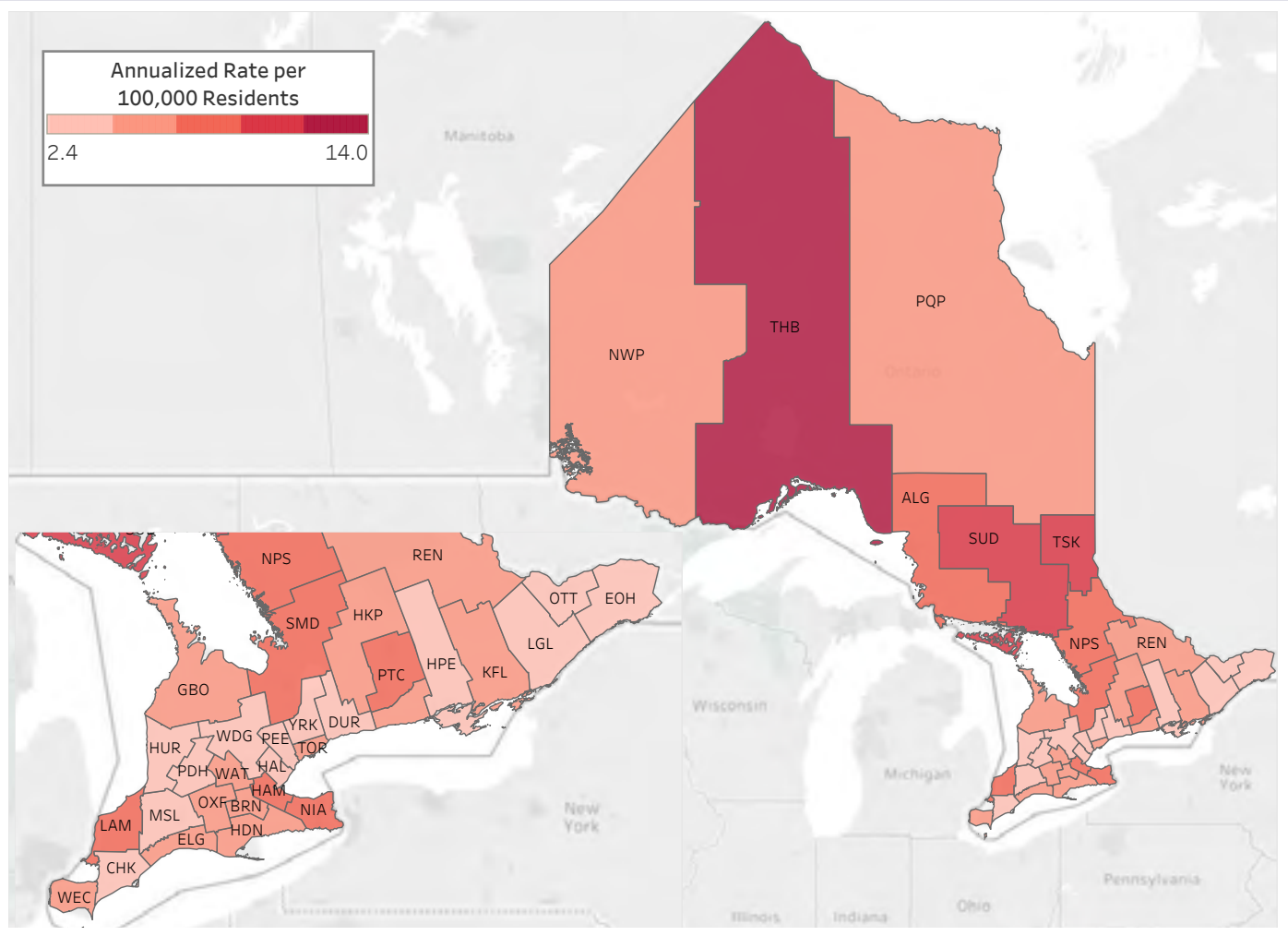




\section{Opioids to Treat Pain}

- The number of people dispensed an opioid to treat pain has remained relatively constant over the last 4 years in Ontario.

- The total volume of opioids dispensed to treat pain has decreased $18 \%$ since January 2015 , largely driven by reductions among long-acting opioid formulations.

- $\quad$ Oxyxodone was the 2nd most commonly dispensed long-acting opioid after hydromorphone in 2016

- $40 \%$ of long-acting opioid prescriptions dispensed to ongoing opioid users to manage pain had daily doses that exceed thresholds in the 2017 Canadian guidelines.

In $2016,11.9 \%$ of Ontarians - amounting to $1,663,181$ individuals - were dispensed an opioid to treat pain.

The monthly percentage of Ontarians who were dispensed an opioid to treat pain has remained relatively constant between July 2012 and March 2017 , with an average of $3.0 \%$ of Ontarians dispensed an opioid each month (Figure 5). However, despite being relatively stable between 2012 and 2014, beginning in 2015 the monthly population exposure to opioids decreased. This resulted in an $18 \%$ reduction in the rate of milligrams of morphine (or equivalent; mg MEQ) dispensed between January 2015 (5,903 mg MEQ per 100 individuals) and March 2017 (4,818 mg MEQ per 100 individuals). This change in trend was largely driven by lower volumes of long-acting opioids being dispensed over this time, with the volume of immediate-release opioids dispensed remaining stable over our study period (Figure 6). The reason for this lower population exposure to long-acting opioids may stem from changes in the types of opioids being dispensed and public health initiatives in Ontario directing doctors as well as pharmacists on safe use and monitoring of opioids. ${ }^{13}$

Figure 5. Patterns in opioids dispensed to treat pain

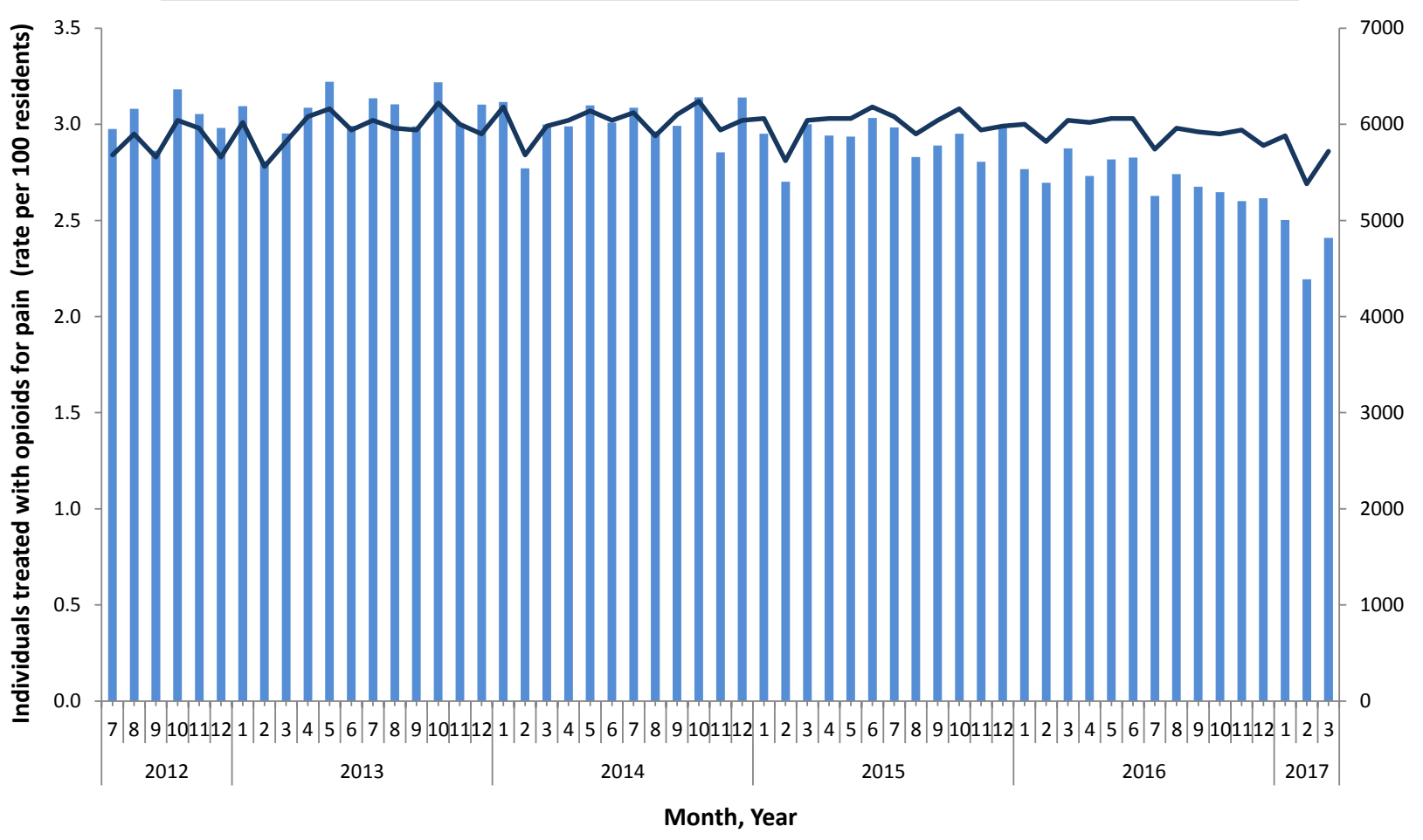

Total volume dispensed —Rate of individuals 
Figure 6. Patterns in total volume of opioids dispensed for pain, by formulation type

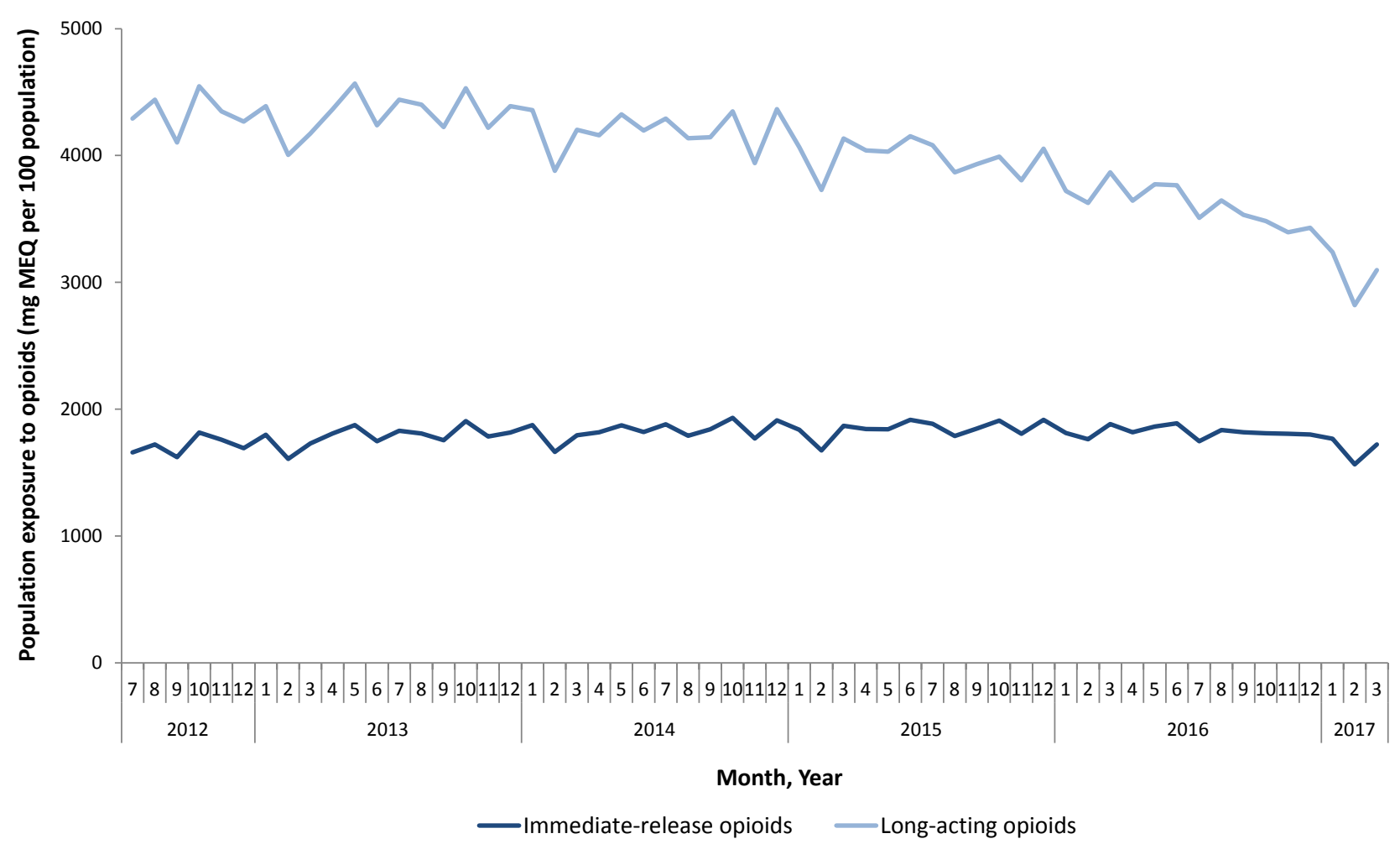

\section{What is 'mg MEQ'?}

Opioids come in a variety of different drugs that vary on a chemical level. These differences change how much of the drug you need (i.e. potency) to reach the same desired analgesic effect. To allow us to compare and combine all drugs together we calculate a 'mg MEQ'.

'mg MEQ' stands for 'milligrams of morphine or equivalent', and is a standardized measure of the total amount of opioid dispensed on a single prescription or more broadly into the community. This is calculated by adding up the total number of milligrams of drug contained in every opioid tablet or patch dispensed, and then converting this into an equivalent morphine dose. Therefore, this allows us to estimate the total amount of opioids dispensed, incorporating the doses of drug and the strength of the particular opioid.

Throughout parts of this section, we use the total amount of mg MEQ dispensed per 100 population as a measure of 'population exposure' to opioids in the community.
A recent report by Health Quality Ontario found that an additional 450,000 prescriptions were dispensed in 2015/16 as compared with 2013/14. ${ }^{6}$ When contextualized with the above findings (i.e. constant rate of individuals and decreasing volume of opioids dispensed), these patterns suggest that in recent years, people treated with opioids for pain are receiving less volume of opioids overall, and are likely being dispensed a lower quantity or dose of opioids on each pharmacy visit. This could indicate a positive move by prescribers and pharmacies to more judiciously prescribe and dispense opioids across the province in recent years.

\section{Types of Opioids to Treat Pain}

In 2016 , nearly all $(1,624,209$ of $1,663,181 ; 98 \%)$ individuals treated with opioids for pain were dispensed an immediate-release opioid. The most commonly dispensed immediate-release opioids were codeine combination products $(52 \%)$, oxycodone combination products $(28 \%$, e.g. Percocet), hydromorphone (16\%, e.g. Dilaudid), and tramadol (11\%, e.g. Tramacet) (Table 4). Among the 
Table 4. Types of opioids dispensed to treat pain, 2016.

\begin{tabular}{|c|c|}
\hline & $\begin{array}{c}\text { Individuals } \\
\mathbf{N}=1,663,181\end{array}$ \\
\hline Immediate-release opioids & $1,624,209(98 \%)$ \\
\hline Codeine Combination & $846,021(52 \%)$ \\
\hline Hydromorphone & $260,686(16 \%)$ \\
\hline Morphine & $93,174(6 \%)$ \\
\hline Oxycodone & $41,708(3 \%)$ \\
\hline Oxycodone Combination & $454,236(28 \%)$ \\
\hline Tramadol & $179,828(11 \%)$ \\
\hline Other* & $61,745(4 \%)$ \\
\hline Long-acting opioids & $183,182(11 \%)$ \\
\hline Codeine & $8,590(5 \%)$ \\
\hline Fentanyl & $24,688(13 \%)$ \\
\hline Hydromorphone & $73,146(40 \%)$ \\
\hline Morphine & $29,429(16 \%)$ \\
\hline Oxycodone & $37,309(20 \%)$ \\
\hline Tramadol & $19,506(11 \%)$ \\
\hline Tapentadol & $5,178(3 \%)$ \\
\hline
\end{tabular}

*includes codeine, fentanyl, meperidine and other rarely used immediate-release opioids (ex. anileridine, pentazocine)

183,182 individuals who were dispensed a longacting opioid in 2016 ( $11 \%$ of all people receiving opioids for pain), the most commonly used opioids were hydromorphone (35\%, e.g. Hydromorph Contin) and oxycodone (18\%, e.g. OxyNEO).

The relatively high use of long-acting tramadol prescribing ( $11 \%$ of people receiving long-acting opioids) is worth noting given that this drug is not reimbursed by the public drug program and therefore has not been well studied in Ontario in the past. Concerns regarding tramadol's safety center on it as a cause of seizures, serotonin toxicity and its unpredictable conversion to an opioid by the liver which leads to difficulties in adjusting dose. ${ }^{14-16}$ Tramadol is commonly used in other regions of the world, including Europe and Australia, where there have been similar concerns about its safety. ${ }^{17-19}$ Future work is needed to understand the patterns of use of tramadol and whether this prevalence of use in Ontario is contributing to overdoses.

\section{New and Ongoing Users of Opioids to Treat Pain}

In 2016, approximately one-third $(613,270$ individuals; $36.9 \%$ ) of people dispensed an opioid to treat pain had a prior opioid exposure in the past year (i.e. ongoing users), and 1,049,911 (63.1\%) were newly initiated on these drugs (i.e. new users) (Table 5). This high proportion of people newly initiating opioids is likely due to the common use of short-term prescription opioids to treat acute pain such as post-surgical and dental pain. ${ }^{20}$

Among new opioid users in 2016, less than 5\% were dispensed a long-acting opioid that same year, and they were dispensed a median of 1 prescription in 2016 (IQR 1-2). The low rate of longacting opioid use among new users is reassuring in light of recommendations in national prescribing guidelines that suggest clinicians first try immediaterelease opioids before escalating patients to longacting formulations. ${ }^{14}$ In contrast, ongoing users of opioids were dispensed a median of 5 prescriptions annually, with one-quarter (25\%) dispensed a long-acting opioid, and $23 \%$ also prescribed a benzodiazepine.

Approximately 2 million opioid prescriptions for pain were dispensed to just over 1 million new opioid users in 2016, compared to almost 7 million prescriptions dispensed to approximately 600,000 ongoing users. On average, new users received immediate-release opioid prescriptions with a relatively short duration (median 5 days) and small number of tablets (median 30 units per prescription). In comparison, immediate-release opioids dispensed to ongoing opioid users tended to be of longer duration and higher quantity (median 14 days; 60 units per prescription). When considering long-acting opioids, there was little difference in the number of units dispensed or the duration of prescriptions between new and ongoing users. These findings - particularly among new opioid users - are somewhat reassuring as they suggest that at the time of opioid initiation, people are not being dispensed large quantities of opioids.

Among immediate-release opioid prescriptions, daily doses above 50mg MEQ were less common, occurring in less than $20 \%$ of prescriptions, and 
Table 5. Opioid use amongst new and ongoing pain users, 2016.

\begin{tabular}{|c|c|c|c|}
\hline \multicolumn{2}{|c|}{ 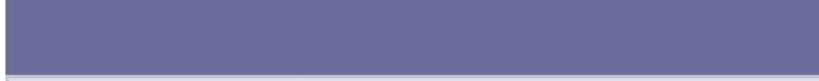 } & New Users & Ongoing Users \\
\hline \multicolumn{2}{|c|}{ Number of Individuals } & $\mathrm{N}=1,049,911$ & $N=613,270$ \\
\hline \multicolumn{2}{|c|}{ Prescriptions per person (Median, IQR*) } & $1(1-2)$ & $5(2-13)$ \\
\hline \multicolumn{2}{|c|}{ Concurrent use of benzodiazepines ( $\mathrm{N}, \%)$} & $33,109(3 \%)$ & $140,210(23 \%)$ \\
\hline \multicolumn{2}{|c|}{ Dispensed an immediate-release opioid (\%) } & $1,044,397(99 \%)$ & $579,812(94 \%)$ \\
\hline \multicolumn{2}{|c|}{ Dispensed a long-acting opioid (N, \%) } & $32,416(3 \%)$ & $150,766(25 \%)$ \\
\hline \multicolumn{2}{|c|}{ Number of prescriptions dispensed } & $\mathrm{N}=1,860,192$ & $N=6,885,264$ \\
\hline \multirow{7}{*}{$\begin{array}{l}\text { Immediate- } \\
\text { release opioid } \\
\text { prescriptions }\end{array}$} & Number of prescriptions (N, \%) & $1,748,522(94 \%)$ & $4,629,106(67 \%)$ \\
\hline & Units† dispensed (Median, IQR) & $30(20-45)$ & $60(28-100)$ \\
\hline & Days' supply (Median, IQR) & $5(3-8)$ & $14(7-30)$ \\
\hline & \multicolumn{3}{|l|}{ Daily dose (N, \%) } \\
\hline & $\leq 50 \mathrm{mg} \mathrm{MEQ}$ & $1,418,658(81 \%)$ & $3,762,352(81 \%)$ \\
\hline & 51-90mg MEQ & $270,663(16 \%)$ & $632,891(14 \%)$ \\
\hline & $>90 \mathrm{mg} \mathrm{MEQ}$ & $59,201(3 \%)$ & $233,863(5 \%)$ \\
\hline \multirow{7}{*}{$\begin{array}{l}\text { Long-acting } \\
\text { opioid } \\
\text { prescriptions }\end{array}$} & Number of prescriptions (\%) & $111,670(6 \%)$ & $2,256,158(33 \%)$ \\
\hline & Units† dispensed (Median, IQR) & $21(13-60)$ & $28(14-60)$ \\
\hline & Days' supply (Median, IQR) & $14(7-30)$ & $15(7-30)$ \\
\hline & \multicolumn{3}{|l|}{ Daily dose (N, \%) } \\
\hline & $\leq 50 \mathrm{mg} \mathrm{MEQ}$ & $73,561(66 \%)$ & $882,260(39 \%)$ \\
\hline & 51-90mg MEQ & $21,139(19 \%)$ & $474,687(21 \%)$ \\
\hline & $>90 \mathrm{mg} \mathrm{MEQ}$ & $16,970(15 \%)$ & $899,211(40 \%)$ \\
\hline
\end{tabular}

${ }^{*} I Q R$ (Interquartile range) is the range from the 25th to 75th percentile.

tDepending on the type of opioid dispensed, units may refer to tablets or patches.

were similar between new and ongoing opioid users (Figure 7). However, the daily dose of long-acting opioid prescriptions was much higher, with only $39 \%$ of prescriptions among ongoing users had a daily dose less than $50 \mathrm{mg}$ MEQ compared to $66 \%$ of prescriptions among new users. Furthermore, $40 \%$ of all long-acting opioid prescriptions dispensed to ongoing opioid users had daily doses exceeding $90 \mathrm{mg}$ MEQ. This is likely reflective of dose escalation that occurs among people using opioids long-term. ${ }^{21}$ Importantly, current national guidelines for the treatment of chronic non-cancer pain suggest that prescribers avoid treating patients with more than $90 \mathrm{mg} M E Q$ daily, and our findings suggest a high degree of prescribing above this level among ongoing opioid users in the province. It should also be noted that the majority of people treated with long-acting opioids were also being dispensed immediate-release opioids. Therefore, it is likely
Figure 7. Daily opioid use among new and ongoing opioid users, 2016.

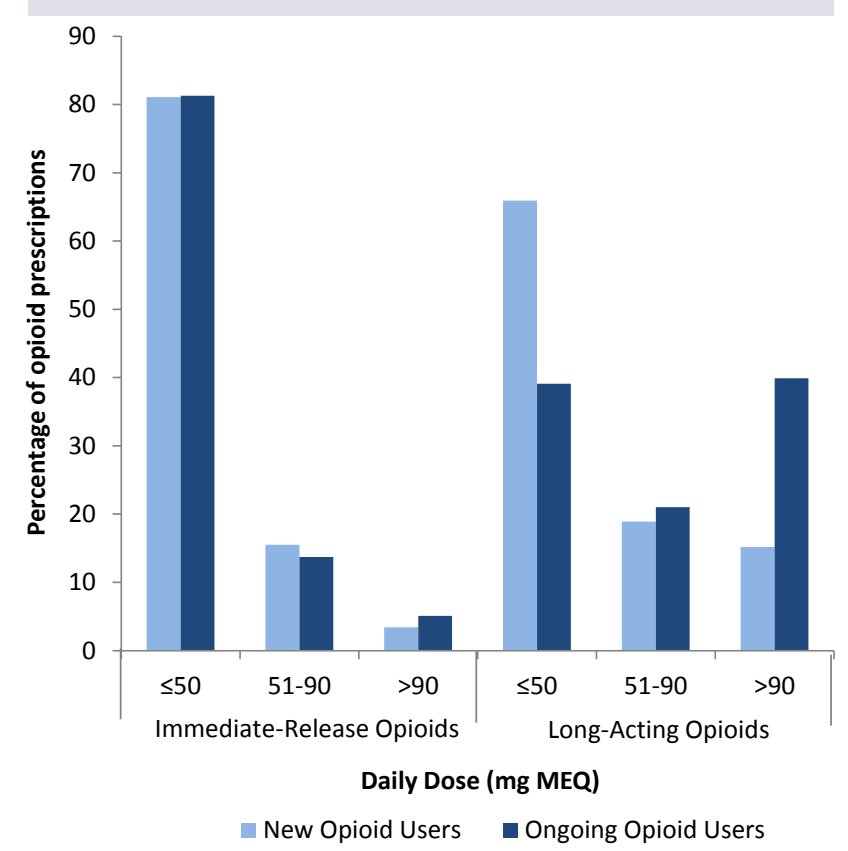


that the average daily dose of opioids dispensed to these individuals was higher than what we report at the prescription level. Overall, these findings suggest that prescribing is frequently occurring outside of guideline recommendations ${ }^{14}$ in Ontario, and that there would need to be considerable changes to clinical practice for prescribers to move towards following these guidelines. It should be noted, however, that some of these prescriptions could have been dispensed to individuals receiving treatment for cancer pain or in palliative care settings where higher doses of opioids may be appropriate..$^{22}$

\section{Opioids to Treat Gough}

- The use of opioids for cough suppression varied seasonally, as expected, with the majority of use occurring in the winter months.

- The average daily dose of opioids to treat cough was very low.

In 2016, $2.3 \%$ of Ontarians (317,890 individuals) were dispensed an opioid for cough suppression.

The monthly rate of people receiving opioids for cough showed a strong seasonal variation, with consistently higher rates ( 0.3 to 0.5 per 100 individuals) in winter months (Figure 8). This finding aligns with patterns of respiratory infections due to colds in these months. ${ }^{23}$ Despite these patterns, the daily dose of opioid prescriptions to treat cough was very low with a mean of $10.9 \mathrm{mg}$ MEQ in 2016 (standard deviation: $10.4 \mathrm{mg} \mathrm{MEQ).}$

Figure 8. Patterns in opioids dispensed to treat cough

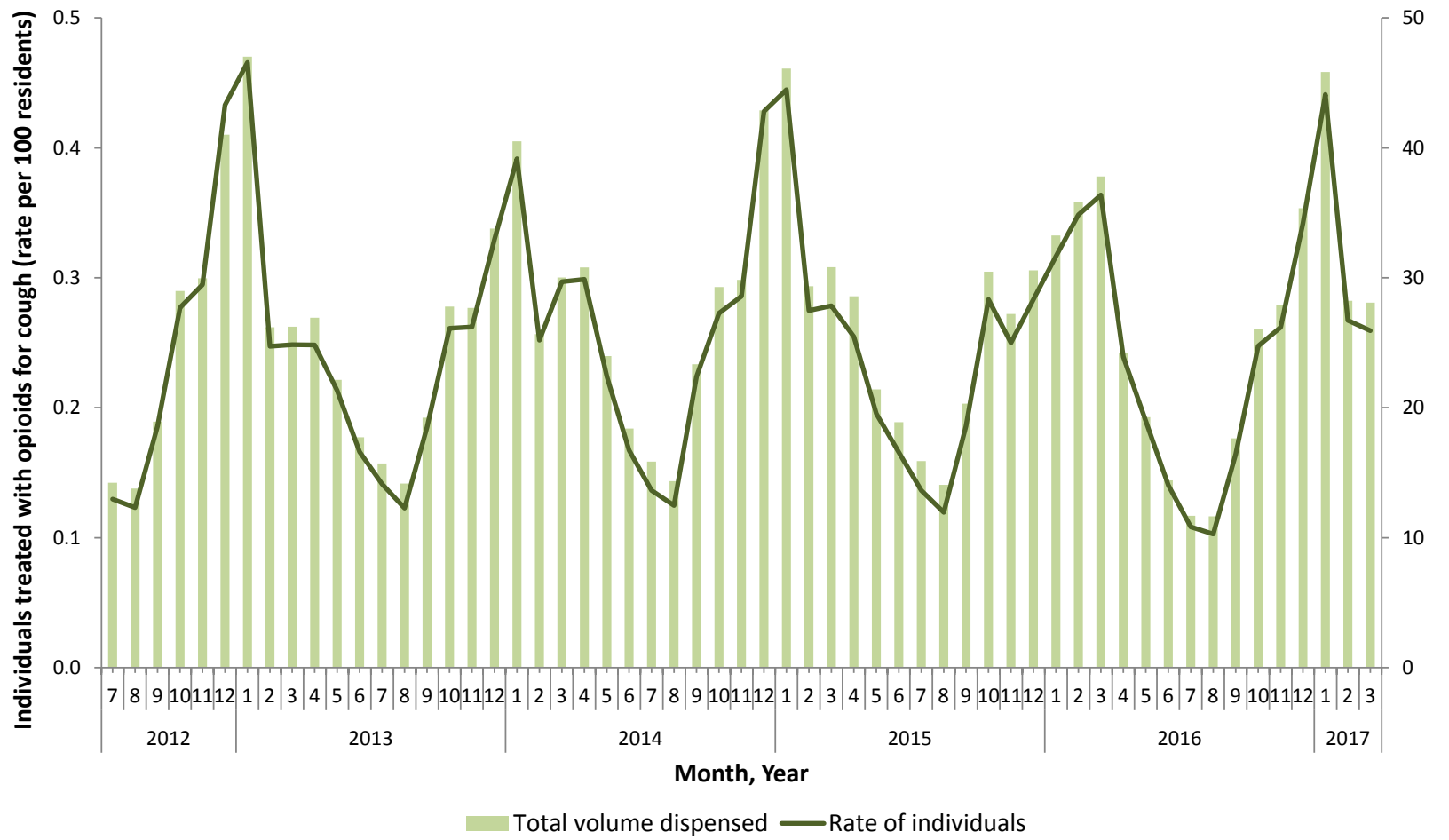




\section{Opioids to Treat Addiction}

- The number and rate of Ontarians accessing opioids to treat addiction has increased, largely driven by uptake of buprenorphine/naloxone.

- In 2016 , almost $30 \%$ of people treated with opioids for addiction were dispensed buprenorphine/ naloxone.

In $2016,0.4 \%$ of Ontarians (57,509 individuals) were dispensed an opioid to treat addiction (methadone or buprenorphine/naloxone). The majority of these individuals received methadone $(\mathrm{N}=40,862 ; 71 \%)$, while $23 \%(\mathrm{~N}=13,300)$ received buprenorphine/naloxone (i.e. Suboxone), and 6\% $(\mathrm{N}=3,347)$ received both at some point over the course of the year.

The monthly rate of people being dispensed these products has climbed steadily in Ontario, increasing by $53 \%$ from 2.2 per 1000 individuals in July 2012 to 3.4 per 1000 in March 2017 (Figure 9). This increase has been observed among both types of opioids used to treat addiction, but the rate of buprenorphine/naloxone use has risen more quickly.
The rate of people dispensed methadone, the most commonly used form of addiction treatment in Ontario, has increased 29\% (from 2.0 to 2.6 per 1000 individuals) from July 2012 to March 2017. In contrast, over that same timeframe, the rate of people dispensed buprenorphine/naloxone increased $269 \%$ (from 0.23 to 0.85 per 1000 individuals). The increasing trend towards the use of buprenorphine/naloxone is likely being driven by a number of factors, including its recent listing as a full benefit on the public drug plan, and programs developed in rural and remote regions to improve access to addiction treatment in Ontario through expanded availability to this drug. ${ }^{24}$

Figure 9. Patterns in opioids dispensed to treat addiction

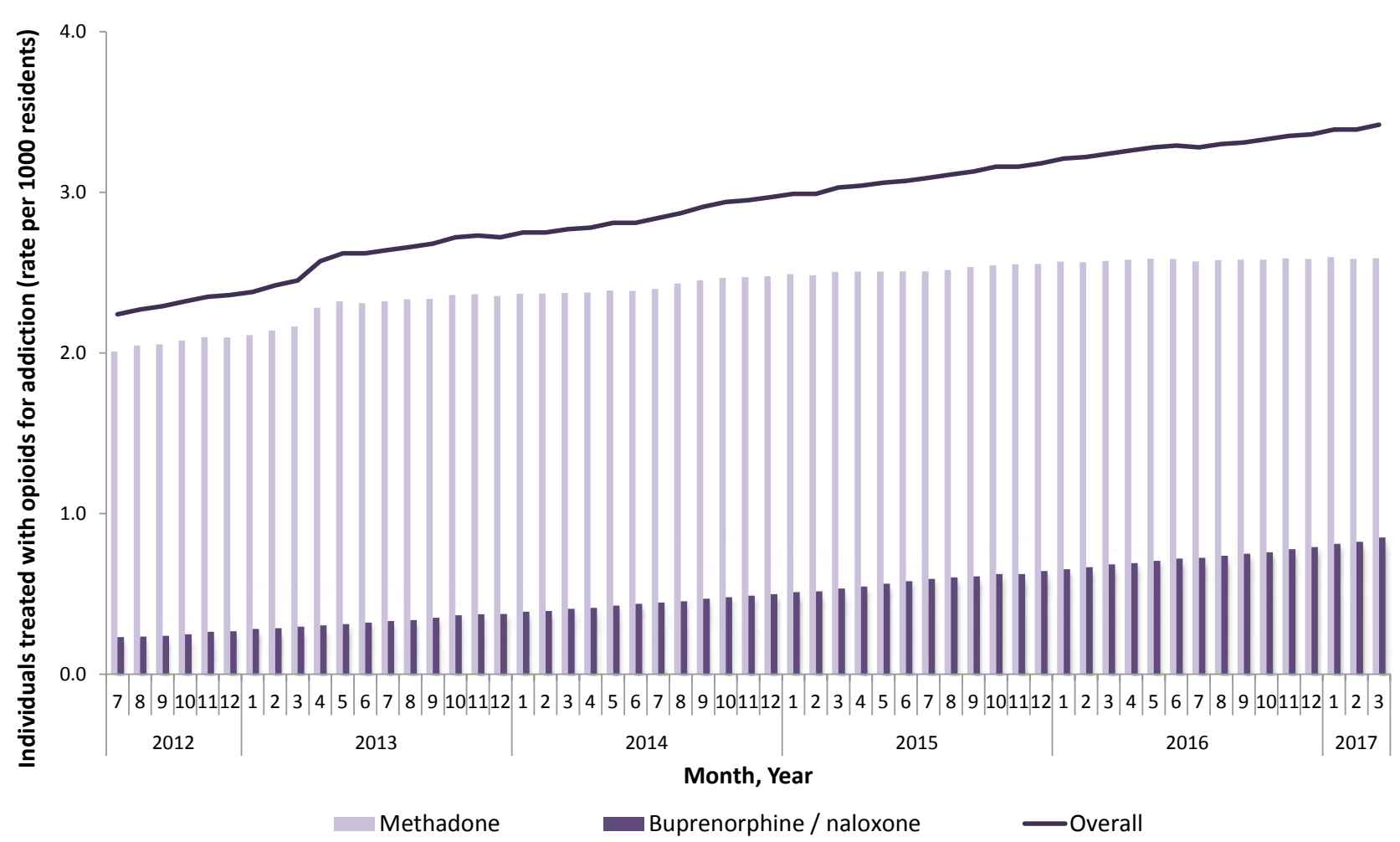




\section{Discussion}

In Ontario, opioid prescribing to treat pain was common, with 1 in 8 people receiving at least one prescription for this indication in 2016. As expected, opioids were rarely used to treat cough, and prescribing for this indication was highly seasonal and at low doses. Importantly, dispensing of opioids to treat addiction has risen considerably over the past 5 years, with 1 in 243 Ontarians treated in 2016. This is likely reflective not only of rising numbers of people with an opioid use disorder in the province over this time, but also increased access to addiction treatment, including buprenorphine/ naloxone. ${ }^{24}$

An important finding of this report is the observed variation in demographic characteristics and the high degree of health services utilization among these individuals. For example, women and the elderly were more likely to be prescribed opioids to treat pain, whereas young adults and men were more likely to be dispensed opioids to treat addiction. This raises questions regarding whether clinical decision-making around opioid prescribing differs between men and women, and whether there are barriers to accessing addiction treatment among women. Furthermore, although opioid prescribing for pain was similarly distributed among all income brackets, over half of people accessing addiction treatment were of low socioeconomic status. This may be reflective of a higher prevalence of other comorbidities and differences in social determinants of health (i.e. unstable housing, childhood trauma, poor education) in low-income populations that may make this vulnerable population more likely to develop an opioid use disorder or to engage in highrisk drug use behaviours. ${ }^{25}$

The report "9 Million Prescriptions" recently published by HQO found that nearly half a million additional opioid prescriptions were dispensed in Ontario in 2015/16 compared with 2013/14. ${ }^{6}$ In this report, we found that the number of people dispensed opioids has remained stable, and that the volume of drug being dispensed (in milligrams of morphine or equivalent) has actually declined considerably over this time. The combination of these findings provides important insight into potential changes in prescribing patterns across the province. In particular, it appears that there have been no increases in the number of people being exposed to opioids, and although a larger number of prescriptions are being dispensed, the amount of opioid dispensed on each prescription is lowering. Interestingly, this pattern of decreasing population exposure to opioids began in 2015 in the midst of many public health initiatives to encourage safe practices of opioid prescribing. ${ }^{13}$ This may, therefore, be reflective of an encouraging trend if physicians and pharmacies are working towards dispensing smaller amounts of opioid at a time. These patterns could also occur if physicians were lowering the daily dose dispensed to their patients, therefore also decreasing the overall amount of opioids being dispensed into the community in Ontario. Although the relatively short duration of prescriptions in 2016 may reinforce these suggestions, more detailed analyses are needed to fully understand these patterns, and to ensure that dose reductions are being conducted in a safe manner.

The geographic variations observed in our analysis provides important insight into areas of high opioid prescribing in Ontario and how these relate to patterns of access to treatment for opioid addiction and rates of opioid-related deaths. While it appears that some areas with high opioid prescribing and death rates (e.g. Thunder Bay District) also have very high rates of both methadone and buprenorphine/naloxone use, there are other regions (i.e. Haliburton, Kawartha, Pine Ridge District Health Unit, Windsor-Essex County Health Unit and Porcupine Health Unit) where rates of opioid prescribing and death are relatively high, but use of opioids to treat addiction is low. This could be suggestive of poor access to addiction treatment services in these areas, which should be further explored.

Finally, we found a high degree of opioid prescribing for pain at daily doses that exceed thresholds recommended in the Canadian clinical guidelines for treatment of chronic non-cancer pain. Although some of this use could be attributable to treatment of pain in palliative care settings, it is unlikely that this small population is driving these trends. Further research is needed to understand the drivers of these findings, and to evaluate the impact of the release of the Canadian guidelines on future opioid treatment patterns. 


\section{Conclusion}

Opioid prescribing, related adverse events, and access to treatment for opioid use disorder continue to be a high priority for clinicians, policy-makers and the general public in Ontario. The findings of this report suggest that recent prescribing patterns may be shifting towards safer practices such as dispensing smaller quantities of opioids. However, in 2016, 1 in 8 Ontarians were dispensed an opioid to treat pain, suggesting that there continues to be a high rate of exposure to these drugs across the province. As the need for improved access to addiction services expands, the geographic variation in access to these services must be considered, with particular attention being made to those regions experiencing high rates of opioid prescribing and related deaths, and poor uptake of addiction treatment options.

\section{References}

1. Ontario Drug Policy Research Network. Latest Trends in Opioid-Related Deaths in Ontario: 1991 to 2015. 2017.

2. Gudin JA, Mogali S, Jones JD, Comer SD. Risks, management, and monitoring of combination opioid, benzodiazepines, and/or alcohol use. Postgrad Med. 2013;125(4):115-130.

3. Ontario Drug Policy Research Network. Opioid Use and Related Adverse Events in Ontario. 2016.

4. Ontario Drug Policy Research Network. Opioid Prescribing and Opioid-Related Hospital Visits in Ontario. 2016.

5. Ontario Ministry of Health and Long-term Care. The Narcotics Safety and Awareness Act. In: Ontario LAo, ed2010.

6. Health Quality Ontario. 9 Million Prescriptions - What we know about the growing use of prescription opioids in Ontario. 2017.

7. Centers for Disease Control and Prevention. Prescription Drug Monitoring Programs (PDMPs). https://www.cdc.gov/ drugoverdose/pdmp/index.html, 2017.

8. Centers for Disease Control and Prevention. Prescription Painkiller Overdoses. https://www.cdc.gov/vitalsigns/ PrescriptionPainkillerOverdoses/index.html, 2017.

9. SAMHSA. Results from the 2013 National Survey on Drug Use and Health: Summary of National Findings. Series H-48 2014; HHS Publication No. (SMA) 14-4863.

10. Canadian Centre on Substance Abuse. National Treatment Indicators Report. 2015.
11. Schuckit MA. Treatment of Opioid-Use Disorders. N Engl J Med. 2016;375(16):1596-1597.

12. World Health Organization. Clinical Guidelines for Withdrawa Management and Treatment of Drug Dependence in Closed Settings. Geneva2009.

13. Safeguarding our Communities Act (Patch for Patch Return Policy), 2015, S.O. 2015, c. 33.

14. Busse JW, Craigie S, Juurlink DN, et al. Guideline for opioid therapy and chronic noncancer pain. CMAJ. 2017;189(18):E659-E666.

15. Young JW, Juurlink DN. Tramadol. CMAJ. 2013;185(8):E352.

16. Owusu Obeng A, Hamadeh I, Smith M. Review of Opioid Pharmacogenetics and Considerations for Pain Management. Pharmacotherapy. Published Online: July 12, 2017 (doi:10.1002/phar.1986) [Epub ahead of print].

17. Pedersen L, Hansen AB, Svendsen K, Skurtveit S, Borchgrevink PC, Fredheim OM. Reimbursement of analgesics for chronic pain. Tidsskr Nor Laegeforen. 2012;132(22):2489-2493.

18. Chevalier P, Smulders M, Chavoshi S, Sostek M, LoCasale R. A description of clinical characteristics and treatment patterns observed within prescribed opioid users in Germany and the UK. Pain Manag. 2014;4(4):267-276.

19. Westergaard ML, Hansen EH, Glumer C, Jensen RH. Prescription pain medications and chronic headache in Denmark: implications for preventing medication overuse. Eur J Clin Pharmacol. 2015;71(7):851-860.

20. Wiland BM WA, Kanar BP, et al. Use of opioid pain relievers following extraction of third molars. Compend Contin Educ Dent. 2015;36:107-111.

21. Kaplovitch E, Gomes T, Camacho X, Dhalla IA, Mamdani MM, Juurlink DN. Sex Differences in Dose Escalation and Overdose Death during Chronic Opioid Therapy: A PopulationBased Cohort Study. PLoS One. 2015;10(8):e0134550.

22. Quigley C. The role of opioids in cancer pain. BMJ. 2005;331(7520):825-829.

23. Moineddin R, Nie JX, Domb G, Leong AM, Upshur RE. Seasonality of primary care utilization for respiratory diseases in Ontario: a time-series analysis. BMC Health Serv Res. 2008;8:160.

24. Strong G. Opioid addiction: a symptom of trauma. 2015. Accessed July 19, 2017, 2017.

25. Galea S, Vlahov D. Social determinants and the health of drug users: socioeconomic status, homelessness, and incarceration. Public Health Rep. 2002;117 Suppl 1:S135-145. 


\section{Appendix}

\section{Ontario Public Health Units}

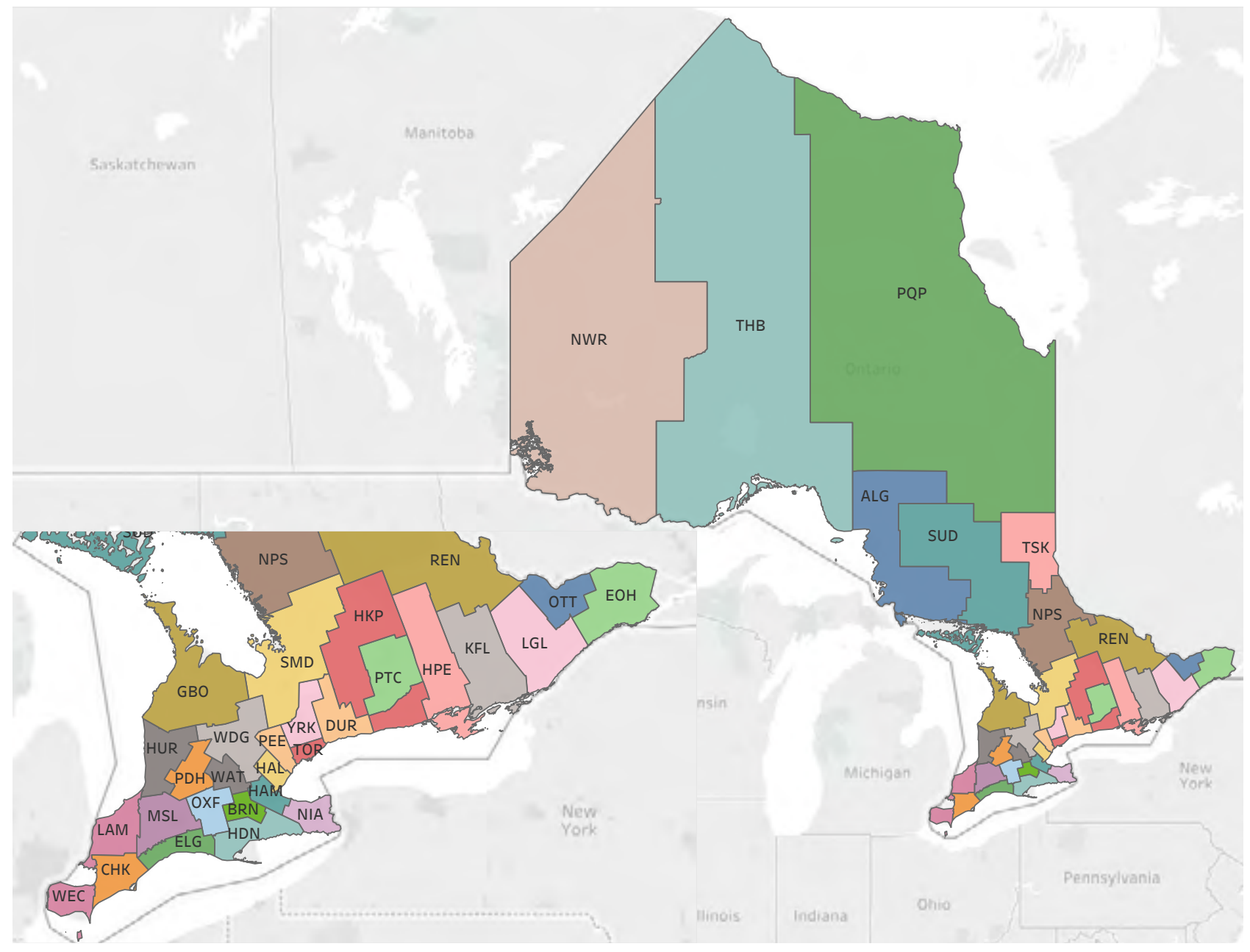

Algoma Public Health (ALG)

$\square$ Brant County Health Unit (BRN)

$\square$ Chatham-Kent Public Health (CHK)

$\square$ City of Hamilton Public Health Services (HAM)

$\square$ Durham Region Health Department (DUR)

$\square$ Eastern Ontario Health Unit (EOH)

$\square$ Elgin-St. Thomas Public Health (ELG)

$\square$ Grey Bruce Health Unit (GBO)

$\square$ Haldimand-Norfolk Health Unit (HDN)

$\square$ Haliburton, Kawartha, Pine Ridge District Health Unit (HKP)

$\square$ Halton Region Health Department (HAL)

$\square$ Hastings Prince Edward Public Health (HPE)

$\square$ Huron County Health Unit (HUR)

$\square$ Kingston, Frontenac and Lennox \& Addington Public Health (KFL)

$\square$ Lambton Public Health (LAM)

$\square$ Leeds, Grenville and Lanark District Health Unit (LGL)

$\square$ Middlesex-London Health Unit (MSL)

$\square$ Niagara Region Public Health (NIA)
North Bay Parry Sound District Health Unit (NPS)

$\square$ Northwestern Health Unit (NWR)

$\square$ Ottawa Public Health (OTT)

$\square$ Oxford County Public Health (OXF)

$\square$ Peel Public Health (PEE)

$\square$ Perth District Health Unit (PDH)

$\square$ Peterborough Public Health (PTC)

$\square$ Porcupine Health Unit (PQP)

$\square$ Region of Waterloo Public Health (WAT)

$\square$ Renfrew County \& District Health Unit (REN)

$\square$ Simcoe Muskoka District Health Unit (SMD)

$\square$ Sudbury \& District Health Unit (SUD)

$\square$ Thunder Bay District Health Unit (THB)

$\square$ Timiskaming Health Unit (TSK)

$\square$ Toronto Public Health (TOR)

$\square$ Wellington-Dufferin-Guelph Public Health (WDG)

$\square$ Windsor-Essex County Health Unit (WEC)

$\square$ York Regional Public Health (YRK) 